\title{
Obituary: A Remembrance of Herbert J. (Tim) Louis MD (1928-2016)
}

\author{
Steven S. Louis MD
}

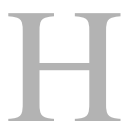

erbert Johnson Louis (Tim), former President of The Association of Bone and Joint Surgeons ${ }^{\circledR}$, passed away at his home in Paradise Valley, Arizona, USA on February 16, 2016. He was the great-grandson of Samuel Curtis Johnson, founder of the SC Johnson \& Sons, as well as an accomplished orthopaedic surgeon, philanthropist, sportsman, Army veteran, mentor, husband, father, grandfather, greatgrandfather, and good friend.

Dr. Louis, my father, studied at Deerfield Academy in Deerfield, MA, Williams College in Williamstown, MA, and Northwestern University Medical School in Chicago. He married Julie deLescaille, his college

The author certifies that his, or any members of his immediate family, has no commercial associations (eg, consultancies, stock ownership, equity interest, patent/licensing arrangements, etc) that might pose a conflict of interest in connection with the submitted article.

The opinions expressed are those of the writers, and do not reflect the opinion or policy of $C O R R^{\circledR}$ or The Association of Bone and Joint Surgeons ${ }^{\circledR}$.

\section{S. S. Louis MD $(\bowtie)$}

Hinsdale Orthopaedics, $550 \mathrm{~W}$. Ogden

Ave., Hinsdale, IL 60521, USA

e-mail: slouis@hoasc.com sweetheart, in 1950, before beginning his medical residency, which he completed at Hines Veterans Administration in Chicago (interrupted by 2 years of medical service as a US Army Captain). He capped his training with a fellowship in England studying under Sir John Charley.

Dr. Louis and his wife Julie (Fig. 1) moved to Phoenix, Arizona, USA in 1961 where he began his professional career in private practice. Shortly after beginning his practice, Dr. Louis realized that his true calling was in education. In 1969, he created and chaired Maricopa County Hospital's orthopaedic residency program, the Phoenix Integrated Orthopaedic Residency, which graduated its first orthopaedic surgeon in 1973.

"Dr. Louis created the first orthopaedic surgery residency program in Arizona, recruited the faculty, and achieved program accreditation on his own, an outstanding accomplishment," Richard Haynes MD, a former 
colleague, said in an interview with Clinical Orthopaedics and Related Research $^{\circledR}$.

As program director and chairman, Dr. Louis trained and graduated 50 residents until his retirement in 1989. His graduates have continued the high standards of care that he represented, and many have chosen to stay in the Phoenix area.

In teaching 50 orthopaedic surgeons during his tenure as residency director, Dr. Louis became more than just an instructor.

"To many of us, he was a second father who demanded of us the same excellence that he demanded of himself," David Ott MD, a former resident, said in an interview with $\operatorname{CORR}^{\circledR}$. "Many of us came in as cocky young doctors ready to implement our training in the latest techniques and boy, did he give us a much needed dose of humility. He told me it was easy for him to teach us orthopaedics, it was behavior that was difficult. He had a temper, and the stories of the "Blue Vein of Louis" will never be forgotten. You knew a line was crossed when his face became red and the blue vein on his forehead protruded."

Preparation and promptness were key components of Dr. Louis' life as a surgeon and educator. If you had not read the articles for journal club, somehow he would find you, according to Dr. Ott. If you showed up for surgery not fully versed in the procedure, the Blue Vein would emerge and he would excuse you for further study, while he found someone else for the case.

"I remember early in residency showing up 5 minutes late for basic science conference," Dr. Ott recalled. "He stopped and asked why I was 65 minutes late. I apologized, telling him I thought the conference had just started. He said it did, and I was 5 minutes late for him and then pointing to each attendee, he said: 'And for him, and him, and him ...' In total, I was 65 minutes late. It would never happen again."

According to James Pritchett MD, another former resident, all residents feared "Big Louie" even though he was warm and often organized interesting social functions.

"He was colorful and not always measured in his comments," Dr. Pritchett told $C O R R^{\circledR}$. "He was an intimidating presence except with patients. Dr. Louis was very confident in his abilities as a surgeon, teacher, golfer, skier, and organizer. He expected confidence in his residents and no clinical challenge was considered beyond the scope of our training. The emotional highs or lows in presenting to Dr. Louis were palpable to the presenter and everyone else in the room."

Dr. Louis had an encyclopedic knowledge of orthopedics. According to Dr. Pritchett, he encouraged the residents in their desire to bring in the advances in internal fixation of fractures and the spine that were controversial at the time.

But his encouragement was often tested.

"Once, when a pair of residents did the absolutely wrong treatment on a child's forearm fracture, he quietly walked up to the view box and said, 'I can't believe one of my boys did this' and left the conference," Dr. Ott recalled. "He was clearly disappointed in them, but like a true parent, also disappointed in himself for their error."

Outside of the residency, Dr. Louis was an active member of the American Academy of Orthopaedic Surgeons, having served on many subcommittees. His career honors include being elected as a member and serving as president for the ABJS, as well as working as an examiner for the American Board of Orthopaedic Surgery.

Most notably to his friends and family, Dr. Louis was a man who selflessly volunteered his time, energy, and finances to a multitude of people, organizations, and causes. In the late 1970s, Dr. Louis was integrally involved in creating the Phoenix Children's Hospital and served on its board since its inception.

Today, Phoenix Children's Hospital is considered one of the largest 
children's hospitals in the country-an 11-story facility with a medical staff of more than 1000 pediatric specialists [1]. But back in 1978, Phoenix was the ninth largest metropolitan region in the country with a population on the upswing and no dedicated children's hospital. As a strong voice in the healthcare community, Dr. Louis was part of a team made up of leaders from the business community and charitable organizations, tasked with locating a potential children's hospital on the campus of an existing hospital-a practical way to limit expenses. In 1983, due to the efforts of the community leadership, Phoenix Children's Hospital opened as an independent hospital within what was then known as Phoenix Good Samaritan Hospital. Throughout the rest of his life, Dr. Louis remained dedicated to Phoenix Children's Hospital. The culmination of his hard work occurred in 2002 when Phoenix Children's became a free-standing hospital [1]. Dr. Louis helped create the first endowed academic chair in Phoenix during this time - the Louis Chair of Pediatric Orthopaedic Surgery at the Phoenix Children's Hospital.

"Dr. Louis is quite simply synonymous with Phoenix Children's Hospital," Dr. Haynes said. "In fact, many of Dr. Louis' colleagues, graduates, and friends refer to the hospital as Louis Children's Hospital. There is no question that without the dedication and foresight of Dr. Louis, Phoenix Children's Hospital would not have evolved in such a spectacular manner."

At home and professionally, he was known to have a wry sense of humor and a keen sense of traditional values. He held himself and others to exacting standards of dress and elocution, but did so with a wink and a smile. Dr. Louis described himself as having a terrible addiction to golf; he never believed himself to be a fine golfer (but he wouldn't mind telling you about his nine holes-in-one, and/or having shot his age on several occasions).

Beyond golf, he had a considerable interest and ability in woodworking and often worked wood into "semifunctional things." He had respect for all living things and had a life-long affinity for pets, including Bainbridge, his beloved and deaf white Labrador retriever, who he proudly trained to be a therapy team member for visits to Phoenix Children's Hospital (Fig. 2).

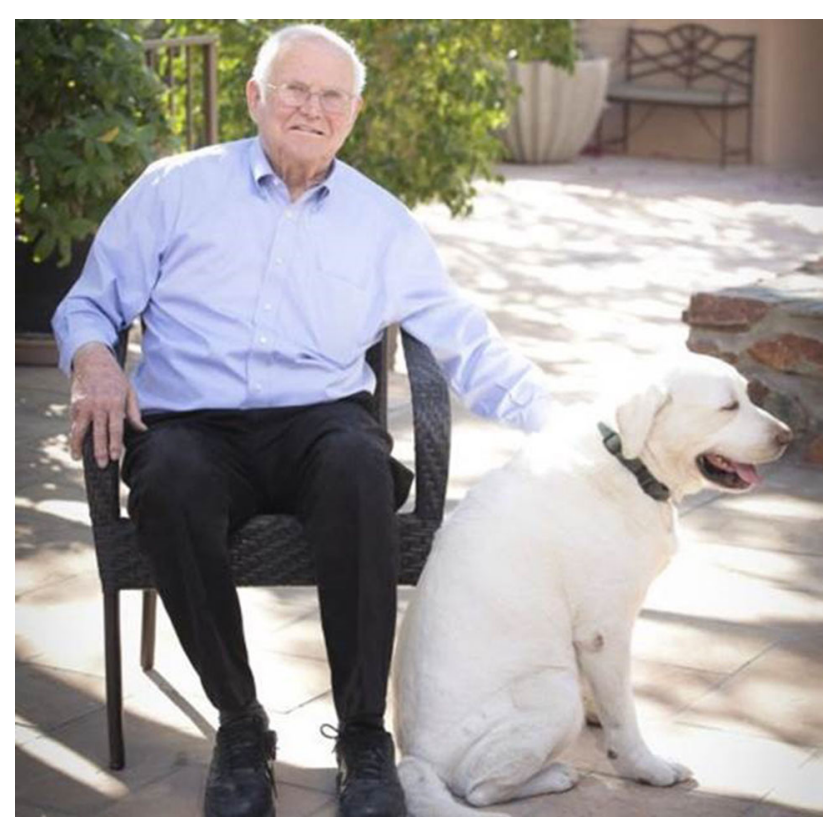

Fig. 2 Dr. Louis trained Bainbridge, his white Labrador retriever, to be a therapy team member for visits to Phoenix Children's Hospital. (Published with permission from Phoenix Children's Hospital). 


\section{Obituary}

Dr. Louis is predeceased by his two brothers, the Honorable John Jeffry Louis, Jr., and Michael William "Mick" Louis. He is survived by his wife Julie, and his six children: Hank Louis, Peggy Moreland, Clif Louis, Carrie Hulburd, Steve Louis, and Tim
Louis. He took enormous amount of pride in his children, 22 grandchildren, and eight great-grandchildren, nurturing their abilities and passions with vigor. His legacy will live through them. He will be sorely, lovingly, and respectfully missed.

\section{References}

1. Phoenix Children's Hospital. History of Phoenix Children's Hospital. Available at: http://www.phoenixchildrens. org/about/history-of-pch. Accessed April 22, 2016. 